\title{
Rapid Hydrothermal Synthesis of Zinc Oxide Nanowires by Annealing Methods on Seed Layers
}

\author{
Jang Bo Shim, ${ }^{1}$ Hyuk Chang, ${ }^{2}$ and Sung-O Kim ${ }^{3}$ \\ ${ }^{1}$ Device Materials Research Center, Korea Research Institute of Chemical Technology, P.O Box 107, Sinseongno 19, \\ Yuseong-gu, Daejeon 305-600, Republic of Korea \\ ${ }^{2}$ Energy Laboratory, Samsung Advanced Institute of Technology, Samsung Electronics, Suwon 446-712, Republic of Korea \\ ${ }^{3}$ Holcombe Department of Electrical and Computer Engineering, Center for Optical Materials Science and Engineering Technologies, \\ Clemson University, Clemson, SC 29634, USA
}

Correspondence should be addressed to Sung-O Kim, sok@clemson.edu

Received 27 September 2010; Revised 17 December 2010; Accepted 7 March 2011

Academic Editor: Cui ChunXiang

Copyright (C) 2011 Jang Bo Shim et al. This is an open access article distributed under the Creative Commons Attribution License, which permits unrestricted use, distribution, and reproduction in any medium, provided the original work is properly cited.

\begin{abstract}
Well-aligned zinc oxide $(\mathrm{ZnO})$ nanowire arrays were successfully synthesized on a glass substrate using the rapid microwave heating process. The $\mathrm{ZnO}$ seed layers were produced by spinning the precursor solutions onto the substrate. Among coatings, the $\mathrm{ZnO}$ seed layers were annealed at $100^{\circ} \mathrm{C}$ for 5 minutes to ensure particle adhesion to the glass surface in air, nitrogen, and vacuum atmospheres. The annealing treatment of the $\mathrm{ZnO}$ seed layer was most important for achieving the high quality of $\mathrm{ZnO}$ nanowire arrays as $\mathrm{ZnO}$ seed nanoparticles of larger than $30 \mathrm{~nm}$ in diameter evolve into $\mathrm{ZnO}$ nanowire arrays. Transmission electron microscopy analysis revealed a single-crystalline lattice of the $\mathrm{ZnO}$ nanowires. Because of their low power (140 W), low operating temperatures $\left(90^{\circ} \mathrm{C}\right)$, easy fabrication (variable microwave sintering system), and low cost (90\% cost reduction compared with gas condensation methods), high quality $\mathrm{ZnO}$ nanowires created with the rapid microwave heating process show great promise for use in flexible solar cells and flexible display devices.
\end{abstract}

\section{Introduction}

$\mathrm{ZnO}$, a wide-band gapsemiconductor $(\mathrm{Eg}=3.37 \mathrm{eV})[1]$, has been synthesized to nanowire via various methods, such as chemical vapor deposition [2-4], vapor-liquid-solid growth $[5,6]$, pulsed laser ablation techniques [7], and solution chemistry [8-11] in constructing nanoscale electronic and optoelectronic devices. Vapor-based synthesis produces high-crystalline and high-aspect-ratio $\mathrm{ZnO}$ nanowires with lengths of several microns, owing to the high synthesis temperatures $\left(450\right.$ to $\left.900^{\circ} \mathrm{C}\right)$ and high vacuum ambient. However, it has a limit for the large scaling of the substrate and flexible electronic device integration as the hydrothermal methods for synthesizing $\mathrm{ZnO}$ nanowires operate at much lower temperatures (below $100^{\circ} \mathrm{C}$ ) and atmospheric pressure. Nevertheless, this hydrothermal method has been used successfully to demonstrate the fabrication of large arrays of vertical $\mathrm{ZnO}$ nanowires on glass, 4-inch diameter Si wafers [12], and plastic substrates [13].

A thorough investigation of hydrothermal $\mathrm{ZnO}$ nanowire synthesis revealed that the time necessary for this synthesis ranged from several hours to several days $[12,14-17]$. To solve this problem, Jung et al. recently investigated tip sonication as a quick method for the aligned $\mathrm{ZnO}$ nanowire synthesis [18], and $\mathrm{Hu}$ et al. studied the possibility of using microwave heating to rapidly synthesize micron-sized $\mathrm{ZnO}$ particles [19]. Microwave heating has also been investigated for rapid synthesis of $\mathrm{ZnO}$ nanowire by Unalan et al. [20]. Most previous research in this area has focused on the rapid synthesis of $\mathrm{ZnO}$ nanowire and postannealing treatment of $\mathrm{ZnO}$ nanowire in air, $\mathrm{O}_{2}$, or vacuum ambient. However, vertical well-aligned $\mathrm{ZnO}$ nanowire arrays and annealing treatment for $\mathrm{ZnO}$ seed layers on glass substrate have yet to be achieved. Consequently, this study annealed in different 


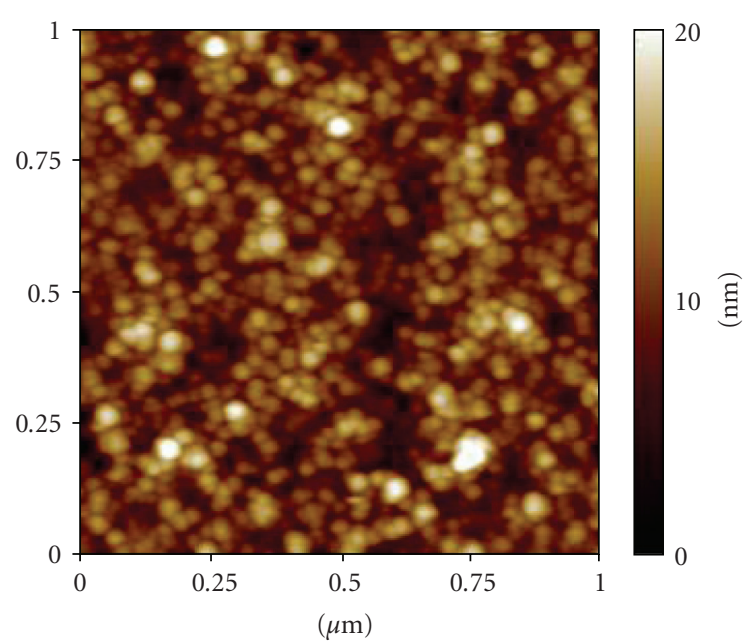

(a)

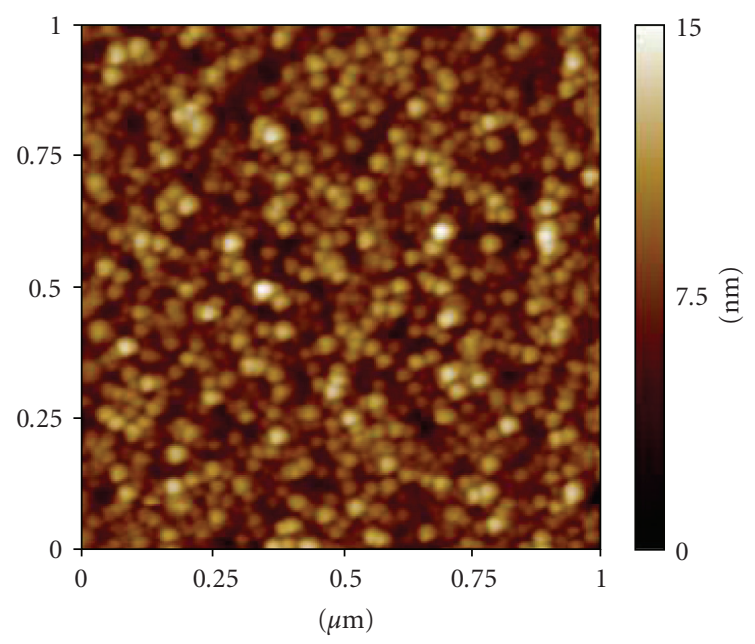

(c)

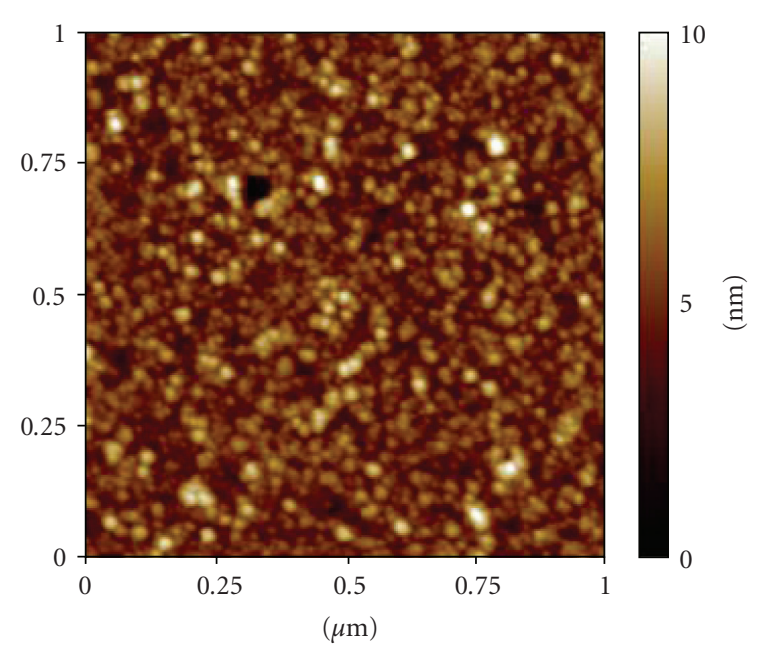

(e)

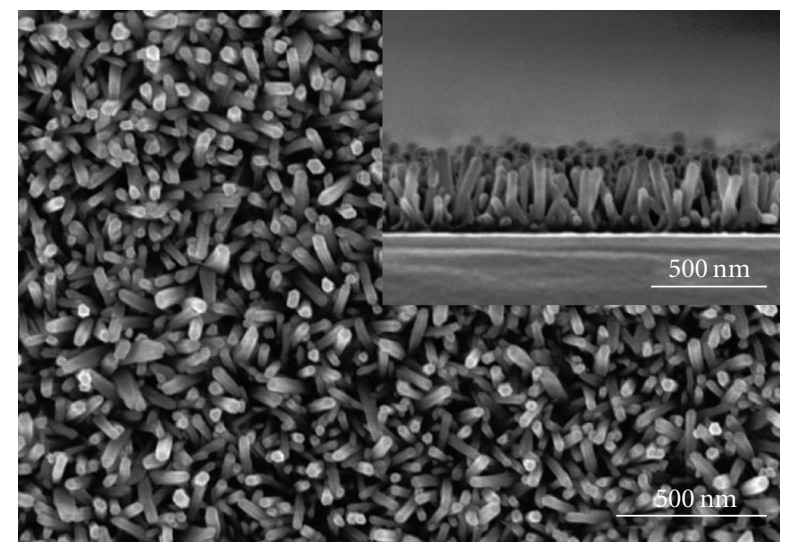

(b)

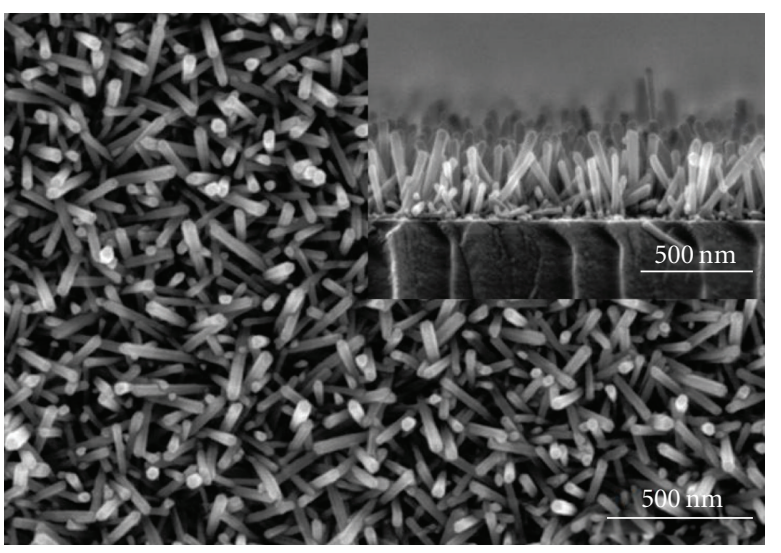

(d)

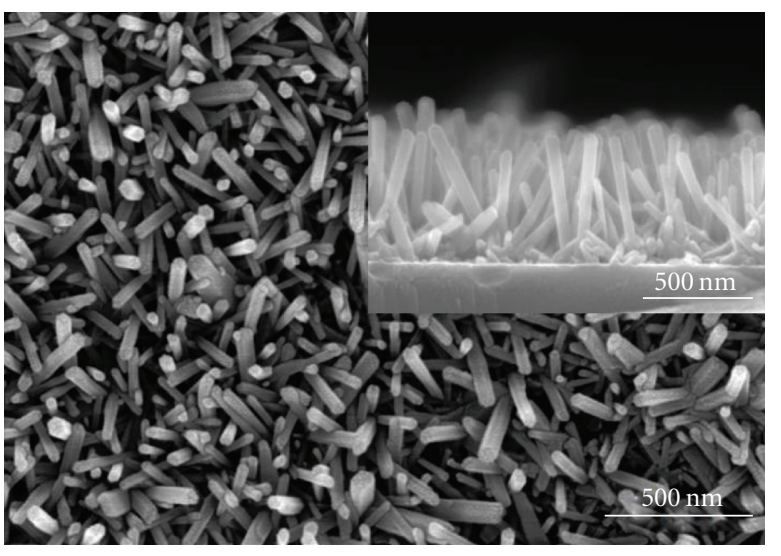

(f)

FIgure 1: AFM images of the $\mathrm{ZnO}$ seed layers with annealing (a) in air, (c) in $\mathrm{N}_{2}$, and (e) in a vacuum; SEM micrographs of the ZnO nanowire arrays under three different seed layer annealing conditions: (b) air, (d) $\mathrm{N}_{2}$, and (f) vacuum. The insets show the cross-sectional view of the $\mathrm{ZnO}$ nanowire arrays. 
conditions for $\mathrm{ZnO}$ seed layer is essential for obtaining high-quality and well-aligned $\mathrm{ZnO}$ nanowire arrays.

\section{Experimental Details}

In this study, we report on the optimal synthesis conditions for preparing well-aligned $\mathrm{ZnO}$ nanowire arrays using the rapid microwave heating process. These well-aligned $\mathrm{ZnO}$ nanowires were grown using a two-step process: (a) preparation of the seed layer and (b) growth of the nanowire arrays. In the first step, coating solutions $(20 \mathrm{mM})$ were prepared by a zinc acetate dihydrate (98\%, Aldrich) and 1-propanol (spectroscopic grade). The $\mathrm{ZnO}$ seed layers were produced by spinning the precursor solutions on a glass substrate. Among coatings, the $\mathrm{ZnO}$ seed layers were annealed at $100^{\circ} \mathrm{C}$ for 5 minutes to ensure particle adhesion to the glass surface in air, nitrogen $\left(\mathrm{N}_{2}\right)$, and vacuum atmospheres. A uniform seed layer was obtained after three layers of spin coating. $\mathrm{ZnO}$ nanowires were then grown by dipping the substrates in a mixture of equimolar $25 \mathrm{mM}$ zinc nitrate hexahydrate $\left(\mathrm{Zn}\left(\mathrm{NO}_{3}\right)_{2} \cdot 6 \mathrm{H}_{2} \mathrm{O}\right.$, Sigma Aldrich) and hexamethylenetetramine (HMTA, Sigma Aldrich) solution in deionized (DI) water and heating with a variable microwave sintering system $(2.45 \mathrm{GHz})$ at $140 \mathrm{~W}$ power setting and atmospheric pressure as the optimal condition. Microwave heating was performed for 10 to $30 \mathrm{~min}$; a revolving turntable within the sintering system ensured a homogeneous heating of the solution. The obtained $\mathrm{ZnO}$ nanowire arrays on the glass substrate were removed from the solution, rinsed with DI water, and dried.

The surface morphology of the $\mathrm{ZnO}$ seed layer was observed by atomic force microscopy (AFM). The morphology and size of the $\mathrm{ZnO}$ nanowires were investigated by field emission scanning electron microscopy (FESEM) (Hitachi S-4800S, operated at $15 \mathrm{kV}$ ), and the crystallinity of the $\mathrm{ZnO}$ nanowires was investigated using high-resolution transmission electron microscopy (HRTEM) (Hitachi 9500, operated at $300 \mathrm{kV}$ ). HRTEM specimens were prepared by scraping wires from the substrates, followed by dispersion in ethanol and then drop cast onto the copper grids. The crystal structure of the $\mathrm{ZnO}$ nanowires was observed using X-ray diffraction (XRD) (Scintag XDS-2000 diffractometer) with $\mathrm{CuK} \alpha$ radiation. The optical characteristics of the as-grown nanowires were investigated using photoluminescence (PL) measurements. The PL measurements were performed at room temperature with the $325 \mathrm{~nm}$ line of a Xenon laser. The X-ray photoelectron spectroscopy (XPS) was measured by using a Kratos AXIS 165 instrument with monochromated $\mathrm{AlK} \alpha$ radiation.

\section{Results and Discussion}

Figure 1 shows the AFM images of the $\mathrm{ZnO}$ seed layers and the SEM images of the $\mathrm{ZnO}$ nanowire arrays in the optimal conditions ( $140 \mathrm{~W}, 2.45 \mathrm{GHz}$, and 30 minutes). At the annealing temperature of $100^{\circ} \mathrm{C}$, the seed layer exhibits no grain forms, whereas, at the annealing temperature of $300^{\circ} \mathrm{C}$, the seed layer contains fine grains [21]. As shown in Figures $1(\mathrm{a}), 1(\mathrm{c})$, and $1(\mathrm{e})$, uniform $\mathrm{ZnO}$ nanoparticles adhering to the glass substrate were observed, which serve as the

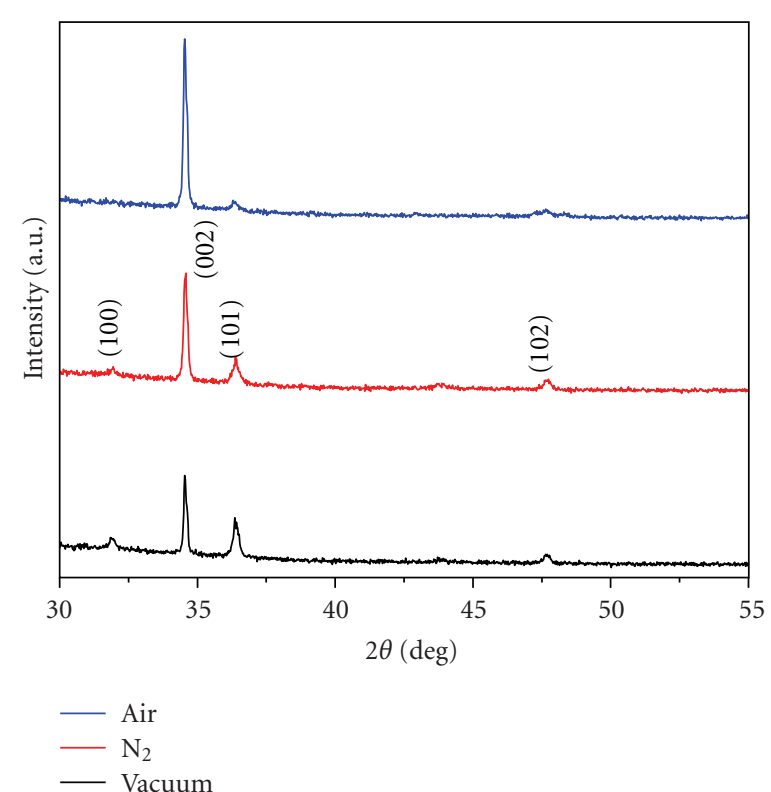

FIGURE 2: XRD patterns of the $\mathrm{ZnO}$ nanowire arrays at three different seed layer annealing conditions: air, $\mathrm{N}_{2}$, and vacuum.

nucleation centers. The initial stage for the $\mathrm{ZnO}$ seed layer is a critical component in obtaining the high quality of uniform $\mathrm{ZnO}$ nanowire arrays. The size distribution of the $\mathrm{ZnO}$ nanoparticles at air annealing conditions is more uniform and narrower compared to nitrogen and vacuum annealing conditions. The dispersion and agglomeration of $\mathrm{ZnO}$ nanoparticles on the glass substrate are not identical due to the different annealing conditions. The higher uniformity of seed layer on air annealing condition, in turn, leads to the growth of higher-quality $\mathrm{ZnO}$ nanowire arrays. The density of $\mathrm{ZnO}$ nanoparticles annealed in air, in $\mathrm{N}_{2}$, and in a vacuum calculated from Figures 1(a), 1(c), and $1(\mathrm{e})$ is $664 \mu \mathrm{m}^{-2}$, $840 \mu \mathrm{m}^{-2}$, and $1160 \mu \mathrm{m}^{-2}$, respectively. Though the density of the $\mathrm{ZnO}$ nanowire arrays on the $\mathrm{ZnO}$ seed layer annealed with the vacuum is approximately $220 \mu \mathrm{m}^{-2}$, as calculated from the SEM image, the density of $\mathrm{ZnO}$ nanoparticles calculated from the AFM image is approximately $1160 \mu \mathrm{m}^{-2}$. This discrepancy indicates that the $\mathrm{ZnO}$ seed nanoparticles of larger than approximately $30 \mathrm{~nm}$ diameter can evolve into $\mathrm{ZnO}$ nanowire arrays. In air annealing conditions, the average diameter of $\mathrm{ZnO}$ nanoparticles increased, which thus enhanced the alignment of the nanowire arrays. If the $\mathrm{ZnO}$ nanowires have a broad size distribution, this interaction will cause the small nanowires under asymmetric force to bend easily, degrading the nanowire alignment [22]. Figures 1(b), $1(\mathrm{~d})$, and 1(f) show the SEM images of top view and crosssectional view for the $\mathrm{ZnO}$ nanowire arrays corresponding to Figures 1(a), 1(c), and 1(e), respectively. These were grown at a fixed temperature $90^{\circ} \mathrm{C}$, while the seed layers were annealed at $100^{\circ} \mathrm{C}$ with air, $\mathrm{N}_{2}$, and vacuum conditions, respectively. The SEM image of the $\mathrm{ZnO}$ nanowire arrays on the $\mathrm{ZnO}$ seed layer annealed at air clearly shows a high density of vertically grown $\mathrm{ZnO}$ nanowire arrays with welldefined hexagonal facets (001). These nanowire arrays have 


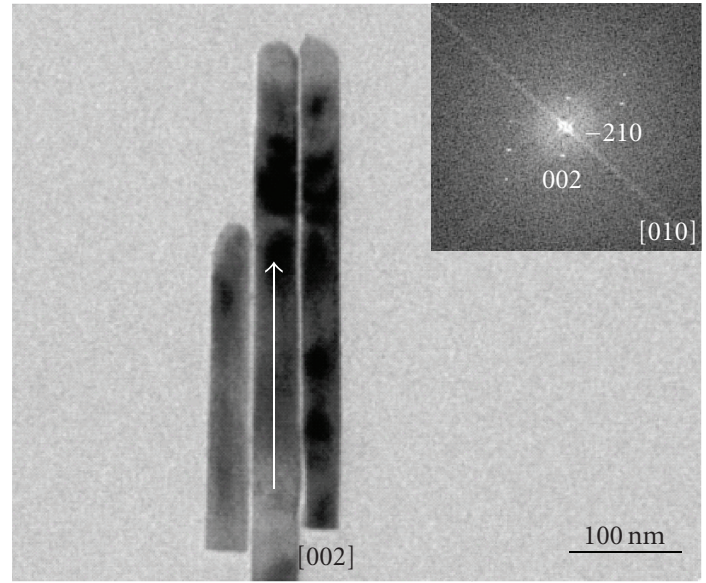

(a)

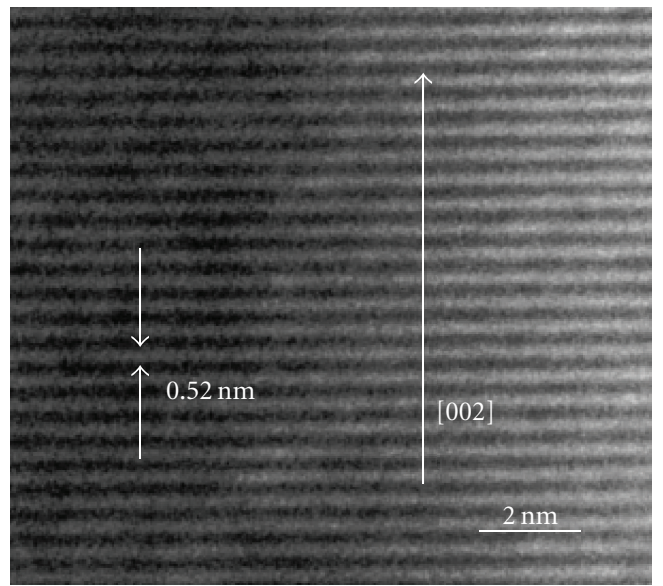

(b)

FIGURE 3: (a) TEM image of the $\mathrm{ZnO}$ nanowire arrays on the $\mathrm{ZnO}$ seed layer annealed in air; the inset shows the corresponding FFT pattern. (b) HRTEM image of the $\mathrm{ZnO}$ nanowire array, in which the lattice spacing is $0.52 \mathrm{~nm}$ along the [002] direction.

a narrow size distribution centered of approximately $38 \mathrm{~nm}$ in diameter in Figure 1(b). The cross-sectional view (inset of Figure 1(b)) of the $\mathrm{ZnO}$ nanowire arrays indicates that the $\mathrm{ZnO}$ nanowire arrays grew vertically with identical lengths of $340 \mathrm{~nm}$. The annealing condition of the $\mathrm{ZnO}$ seed layer is a key influence on the nucleation of the $\mathrm{ZnO}$ nanowire array. Furthermore, the $\mathrm{ZnO}$ nanowire arrays on the $\mathrm{ZnO}$ seed layer annealed at air are well aligned both vertically and uniformly (Figure 1(b)). The well-defined crystallographic planes of the hexagonal-shaped nanowires can be clearly identified, providing strong evidence that the $\mathrm{ZnO}$ nanowire arrays orientate along the $\mathrm{c}$-axis.

Figure 2 shows the XRD patterns of the $\mathrm{ZnO}$ nanowire arrays. It did not appear that any other characteristic peaks corresponding to the impurities of the precursors such as zinc nitrate and zinc hydroxide were observed in the XRD patterns. At the $\mathrm{ZnO}$ nanowire arrays on the $\mathrm{ZnO}$ seed layer annealed in air, a very strong (002) diffraction peak and a very weak (101) peak are observed, indicating a high caxis orientation of the $\mathrm{ZnO}$ nanowire array. In addition, the intensity of the (002) diffraction peak is the strongest, compared to other samples annealed in both $\mathrm{N}_{2}$ and vacuum conditions. This result, in accordance with its SEM image of Figure 1(b), implies its perfect c-axis orientation. However, for the $\mathrm{ZnO}$ nanowire arrays on the $\mathrm{ZnO}$ seed layer annealed in a vacuum, the (002) diffraction peak weakens while the (100) and (101) peaks slightly increase in strength, indicating its tendency toward random orientation. These conclusions closely match the SEM image of the $\mathrm{ZnO}$ nanowire arrays observed in Figure 1(f). The previous XRD investigation of the seed layers annealed at $100^{\circ} \mathrm{C}$ by Asakuma et al. indicates a nearly amorphous structure which agrees with our result [23]. However, the $\mathrm{ZnO}$ nanowire arrays are highly (002) plane-oriented on an amorphous $\mathrm{ZnO}$ seed layer. This orientation indicates that the $\mathrm{ZnO}$ nanowire arrays prepared by the rapid microwave heating process have preferential orientation along the (002) plane on the seed layer without a certain orientation.
The TEM image and the corresponding fast Fourier transform (FFT) pattern are shown in Figure 3(a). Here, it is clearly evident that individual $\mathrm{ZnO}$ nanowire arrays with a diameter of $38 \mathrm{~nm}$ grown along the [002] direction possess a single-crystalline wurtzite structure. The high-resolution TEM image in Figure 3(b) also shows that the $\mathrm{ZnO}$ nanowire array is structurally uniform. We also see the clear d-spacing of (002) crystal planes, confirming that the $\mathrm{ZnO}$ nanowire arrays grown with the rapid microwave heating process are preferentially oriented in the c-axis direction.

The PL spectrum shown in Figure 4 was derived at room temperature. The peak due to the near-bandgap edge emission of the wide-bandgap $\mathrm{ZnO}$ is centered at $380 \mathrm{~nm}$. At the $\mathrm{ZnO}$ nanowire arrays on the $\mathrm{ZnO}$ seed layer annealed in air, the defect-related green emission $(565 \mathrm{~nm})$ of the $\mathrm{ZnO}$ nanowire arrays is lower than in the $\mathrm{N}_{2}$ and vacuum annealing conditions. The green emission is also known to be a deep-level emission caused by the impurities and structural defects in the crystal (e.g., oxygen vacancies, zinc interstitials) [24]. According to the annealing conditions, the PL peak in the green emission region is gradually enhanced, which is believed to result from oxygen vacancies. Therefore, it is suggested that the $\mathrm{ZnO}$ nanowire arrays may reduce the defect density and hence lower the defect-related emission caused by the $\mathrm{ZnO}$ seed layer annealed in air conditions. Moreover, the $\mathrm{ZnO}$ nanowire arrays on the $\mathrm{ZnO}$ seed layer annealed in air have a highly delineated (002) orientation and vertical alignment.

Figure 5 shows XPS spectra of O1s for $\mathrm{ZnO}$ nanowire arrays, fitted with Gaussian-Lorentz distribution $(70: 30$ ratio). The O1s peak was constructed of subpeaks at $527.2 \mathrm{eV}$ and $528.5 \mathrm{eV}$, respectively. The peak with low binding energy $(527.2 \mathrm{eV})$ corresponds to $\mathrm{O}^{2-}$ on normal wurtzite structure of a $\mathrm{ZnO}$ single crystal [25]. Another peak centered at $528.5 \mathrm{eV}$ is attributed to $\mathrm{O}^{2-}$ in the oxygen vacancies within the $\mathrm{ZnO}$ matrix [26]. The O1s peaks for the $\mathrm{ZnO}$ nanowire arrays on the $\mathrm{ZnO}$ seed layer annealed at vacuum have a shoulder at higher binding energy as shown in Figure 5(c), 


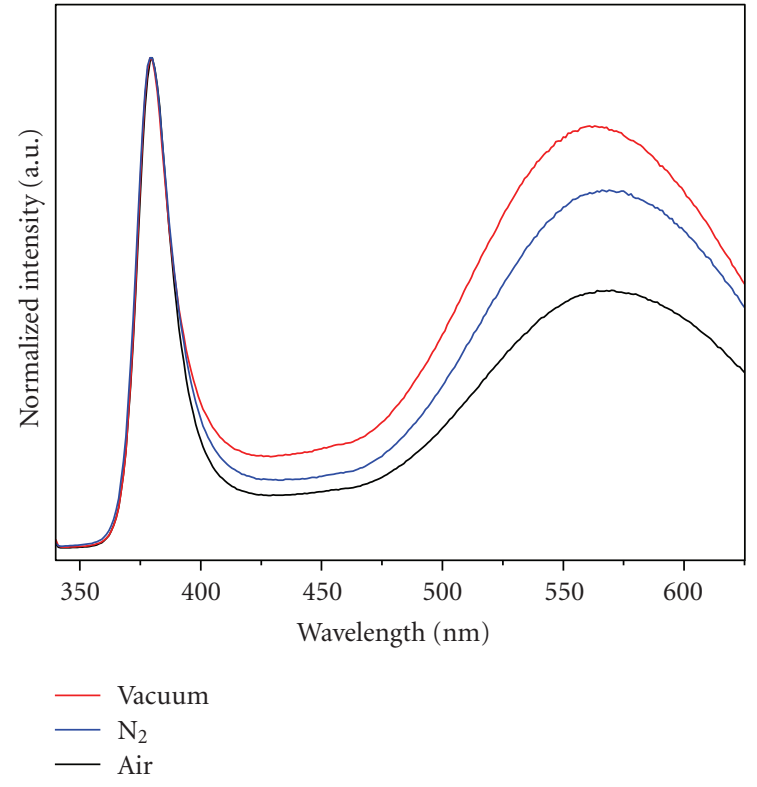

Figure 4: Normalized room temperature PL spectra of the $\mathrm{ZnO}$ nanowire arrays using $325 \mathrm{~nm}$ line as the excitation source.

which gradually decreases for annealed samples in $\mathrm{N}_{2}$ and in air. From the observation of O1s peaks, it is clear that the oxygen vacancies of the $\mathrm{ZnO}$ nanowire arrays decrease with annealing in air conditions. Annealing in $\mathrm{N}_{2}$ and vacuum can cause a deviation from the stoichiometric state, resulting in large oxygen deficiencies [27]. These oxygen deficiencies were decreased by $\mathrm{O}$ that was complemented with annealing in air. These results indicate that the stoichiometry and structure of $\mathrm{ZnO}$ seed layers annealed in air are superior to those of $\mathrm{ZnO}$ layers annealed in both $\mathrm{N}_{2}$ a vacuum. The XPS measurement supports this PL observation. These observations indicate that the $\mathrm{ZnO}$ nanowire arrays on the $\mathrm{ZnO}$ seed layer annealed at vacuum degrade the nanowire quality, thus creating oxygen vacancies.

\section{Conclusion}

High-quality and well-aligned $\mathrm{ZnO}$ nanowire arrays were successfully synthesized on glass substrate by the rapid microwave heating process. We verified that the annealing treatment for $\mathrm{ZnO}$ seed layer was very important for achieving the high quality of $\mathrm{ZnO}$ nanowire arrays as $\mathrm{ZnO}$ seed nanoparticles of larger than $30 \mathrm{~nm}$ in diameter evolve into $\mathrm{ZnO}$ nanowire arrays. The $\mathrm{ZnO}$ nanowire arrays on the $\mathrm{ZnO}$ seed layer annealed at air are highly c-axis-oriented and perpendicular to the substrate with high crystalline quality compared with $\mathrm{N}_{2}$ and vacuum annealed $\mathrm{ZnO}$ nanowires. The PL measurements show that the $\mathrm{ZnO}$ seed layer annealed in air yields low levels of oxygen vacancies in the $\mathrm{ZnO}$ nanowire arrays. The high-quality $\mathrm{ZnO}$ nanowires created with the rapid microwave heating process show a great promise for use in flexible solar cells, flexible displays, and other flexible devices with low power, low growth temperature, short growth time, easy fabrication, and low cost.

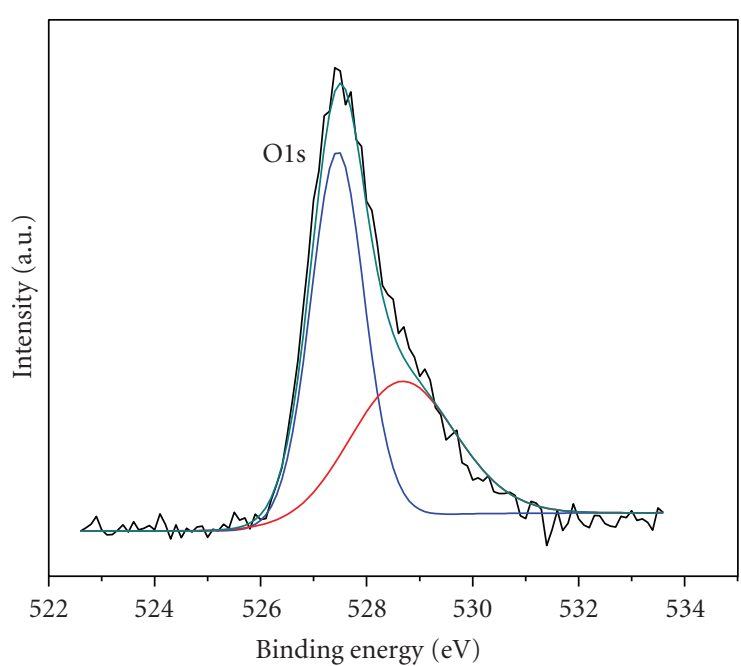

(a)

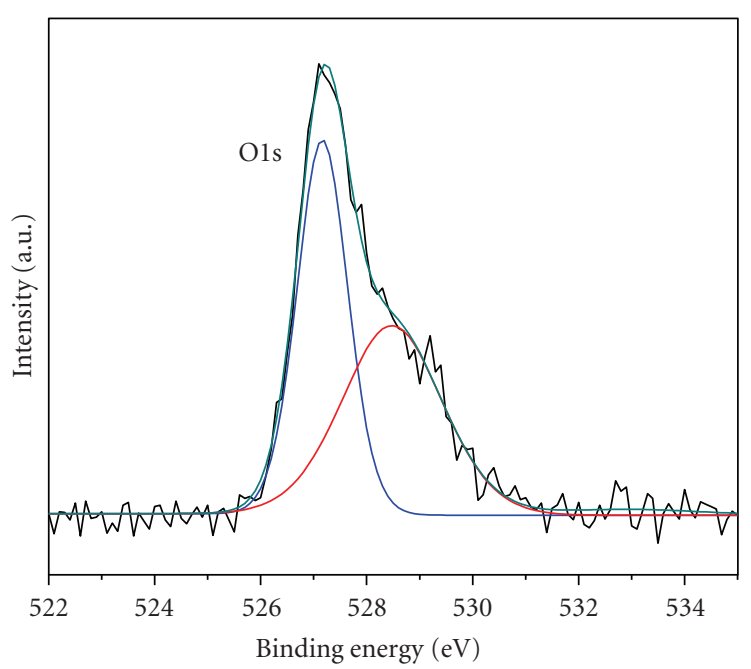

(b)

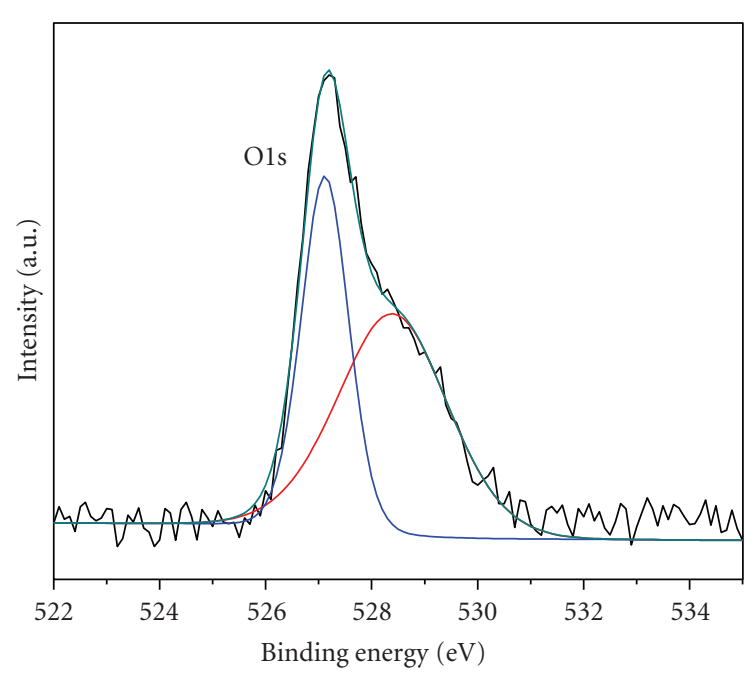

(c)

FIGURE 5: XPS spectra of the $\mathrm{ZnO}$ nanowire arrays at three different seed layer annealing conditions: (a) air, (b) $\mathrm{N}_{2}$, and (c) vacuum. 


\section{Acknowledgments}

The authors wish to thank Samsung Advanced Institute of Technology in Samsung Electronics and the Center for Optical Materials Science and Engineering Technologies (COMSET) in Clemson University for their financial support. The authors also thank Dr. T. Darroudi, Dr. H. Qian, and Dr. J. S. Hudson of Clemson University Electron Microscope Facility for technical assistance and Dr. J. E. Harriss for the Microstructures Laboratory.

\section{References}

[1] D. C. Reynolds, D. C. Look, B. Jogai et al., "Neutral-donorbound-exciton complexes in ZnO crystals," Physical Review B, vol. 57, no. 19, pp. 12151-12155, 1998.

[2] J. J. Wu and S. C. Liu, "Low-temperature growth of well-aligned $\mathrm{ZnO}$ nanorods by chemical vapor deposition," Advanced Materials, vol. 14, no. 3, pp. 215-218, 2002.

[3] B. Xiang, P. Wang, X. Zhang et al., "Rational synthesis of ptype zinc oxide nanowire arrays using simple chemical vapor deposition," Nano Letters, vol. 7, no. 2, pp. 323-328, 2007.

[4] W. I. Park, G. C. Yi, M. Kim, and S. J. Pennycook, “ZnO nanoneedles grown vertically on Si substrates by non-catalytic vapor-phase epitaxy," Advanced Materials, vol. 14, no. 24, pp. 1841-1843, 2002.

[5] X. Wang, J. Song, P. Li et al., "Growth of uniformly aligned $\mathrm{ZnO}$ nanowire heterojunction arrays on $\mathrm{GaN}$, $\mathrm{AlN}$, and $\mathrm{Al}_{0.5} \mathrm{Ga}_{0.5} \mathrm{~N}$ substrates," Journal of the American Chemical Society, vol. 127, no. 21, pp. 7920-7923, 2005.

[6] S. J. Young, L. W. Ji, S. J. Chang et al., "Nanoscale mechanical characteristics of vertical $\mathrm{ZnO}$ nanowires grown on $\mathrm{ZnO}: \mathrm{Ga}$ /glass templates," Nanotechnology, vol. 18, no. 22, Article ID 225603, 2007.

[7] YE. Sun, G. M. Fuge, and M. N. R. Ashfold, "Growth of aligned $\mathrm{ZnO}$ nanorod arrays by catalyst-free pulsed laser deposition methods," Chemical Physics Letters, vol. 396, no. 1-3, pp. 2126, 2004.

[8] S. Yamabi and H. Imai, "Growth conditions for wurtzite zinc oxide films in aqueous solutions," Journal of Materials Chemistry, vol. 12, no. 12, pp. 3773-3778, 2002.

[9] L. Vayssieres, "Growth of arrayed nanorods and nanowires of ZnO from aqueous solutions," Advanced Materials, vol. 15, no. 5, pp. 464-466, 2003.

[10] Z. R. Tian, J. A. Voigt, J. Liu et al., "Complex and oriented ZnO nanostructures," Nature Materials, vol. 2, no. 12, pp. 821-826, 2003.

[11] L. E. Greene, B. D. Yuhas, M. Law, D. Zitoun, and P. Yang, "Solution-grown zinc oxide nanowires," Inorganic Chemistry, vol. 45, no. 19, pp. 7535-7543, 2006.

[12] L. E. Greene, M. Law, J. Goldberger et al., "Low-temperature wafer-scale production of $\mathrm{ZnO}$ nanowire arrays," Angewandte Chemie, vol. 42, no. 26, pp. 3031-3034, 2003.

[13] J. B. Cui, C. P. Daghlian, U. J. Gibson, R. Püsche, P. Geithner, and L. Ley, "Low-temperature growth and field emission of ZnO nanowire arrays," Journal of Applied Physics, vol. 97, no. 4, Article ID 044315, 7 pages, 2005.

[14] L. Vayssieres, K. Keis, S. E. Lindquist, and A. Hagfeldt, "Purpose-built anisotropie metal oxide material: 3D highly oriented microrod array of ZnO," Journal of Physical Chemistry $B$, vol. 105 , no. 17 , pp. 3350-3352, 2001.
[15] K. Govender, D. S. Boyle, P. O’Brien, D. Binks, D. West, and D. Coleman, "Room-temperature lasing observed from $\mathrm{ZnO}$ nanocolumns grown by aqueous solution deposition," Advanced Materials, vol. 14, no. 17, pp. 1221-1224, 2002.

[16] X. Ma, H. Zhang, Y. Ji, J. Xu, and D. Yang, "Sequential occurrence of $\mathrm{ZnO}$ nanopaticles, nanorods, and nanotips during hydrothermal process in a dilute aqueous solution," Materials Letters, vol. 59, no. 27, pp. 3393-3397, 2005.

[17] M. Law, L. E. Greene, J. C. Johnson, R. Saykally, and P. Yang, "Nanowire dye-sensitized solar cells," Nature Materials, vol. 4, no. 6, pp. 455-459, 2005.

[18] S. H. Jung, E. Oh, K. H. Lee, W. Park, and S. H. Jeong, "A sonochemical method for fabricating aligned $\mathrm{ZnO}$ nanorods," Advanced Materials, vol. 19, no. 5, pp. 749-753, 2007.

[19] X. L. Hu, Y. J. Zhu, and S. W. Wang, "Sonochemical and microwave-assisted synthesis of linked single-crystalline $\mathrm{ZnO}$ rods," Materials Chemistry and Physics, vol. 88, no. 2-3, pp. 421-426, 2004.

[20] H. E. Unalan, P. Hiralal, N. Rupesinghe, S. Dalal, W. I. Milne, and G. A. J. Amaratunga, "Rapid synthesis of aligned zinc oxide nanowires," Nanotechnology, vol. 19, no. 25, Article ID 255608, 2008.

[21] J. -S. Huang and C. -F. Lin, "Influences of $\mathrm{ZnO}$ sol-gel thin film characteristics on $\mathrm{ZnO}$ nanowire arrays prepared at low temperature using all solution-based processing," Journal of Applied Physics, vol. 103, no. 1, Article ID 014304, 2008.

[22] M. Wang, C. H. Ye, Y. Zhang, H. X. Wang, X. Y. Zeng, and L. D. Zhang, "Seed-layer controlled synthesis of well-aligned $\mathrm{ZnO}$ nanowire arrays via a low temperature aqueous solution method," Journal of Materials Science: Materials in Electronics, vol. 19, no. 3, pp. 211-216, 2008.

[23] N. Asakuma, H. Hirashima, H. Imai, T. Fukui, and M. Toki, "Crystallization and reduction of sol-gel-derived zinc oxide films by irradiation with ultraviolet lamp," Journal of Sol-Gel Science and Technology, vol. 26, no. 1-3, pp. 181-184, 2003.

[24] Q. Ahsanulhaq, A. Umar, and Y. B. Hahn, "Growth of aligned $\mathrm{ZnO}$ nanorods and nanopencils on $\mathrm{ZnO} / \mathrm{Si}$ in aqueous solution: growth mechanism and structural and optical properties," Nanotechnology, vol. 18, no. 11, Article ID 115603, 2007.

[25] B. J. Coppa, R. F. Davis, and R. J. Nemanich, "Gold Schottky contacts on oxygen plasma-treated, n-type $\mathrm{ZnO}(000 \overline{\mathbf{1}})$," Applied Physics Letters, vol. 82, no. 3, pp. 400-402, 2003.

[26] M. Chen, X. Wang, Y. H. Yu et al., "X-ray photoelectron spectroscopy and auger electron spectroscopy studies of Aldoped ZnO films," Applied Surface Science, vol. 158, no. 1, pp. 134-140, 2000.

[27] X. Q. Wei, B. Y. Man, M. Liu, C. S. Xue, H. Z. Zhuang, and C. Yang, "Blue luminescent centers and microstructural evaluation by XPS and Raman in $\mathrm{ZnO}$ thin films annealed in vacuum, N and O," Physica B, vol. 388, no. 1-2, pp. 145-152, 2007. 

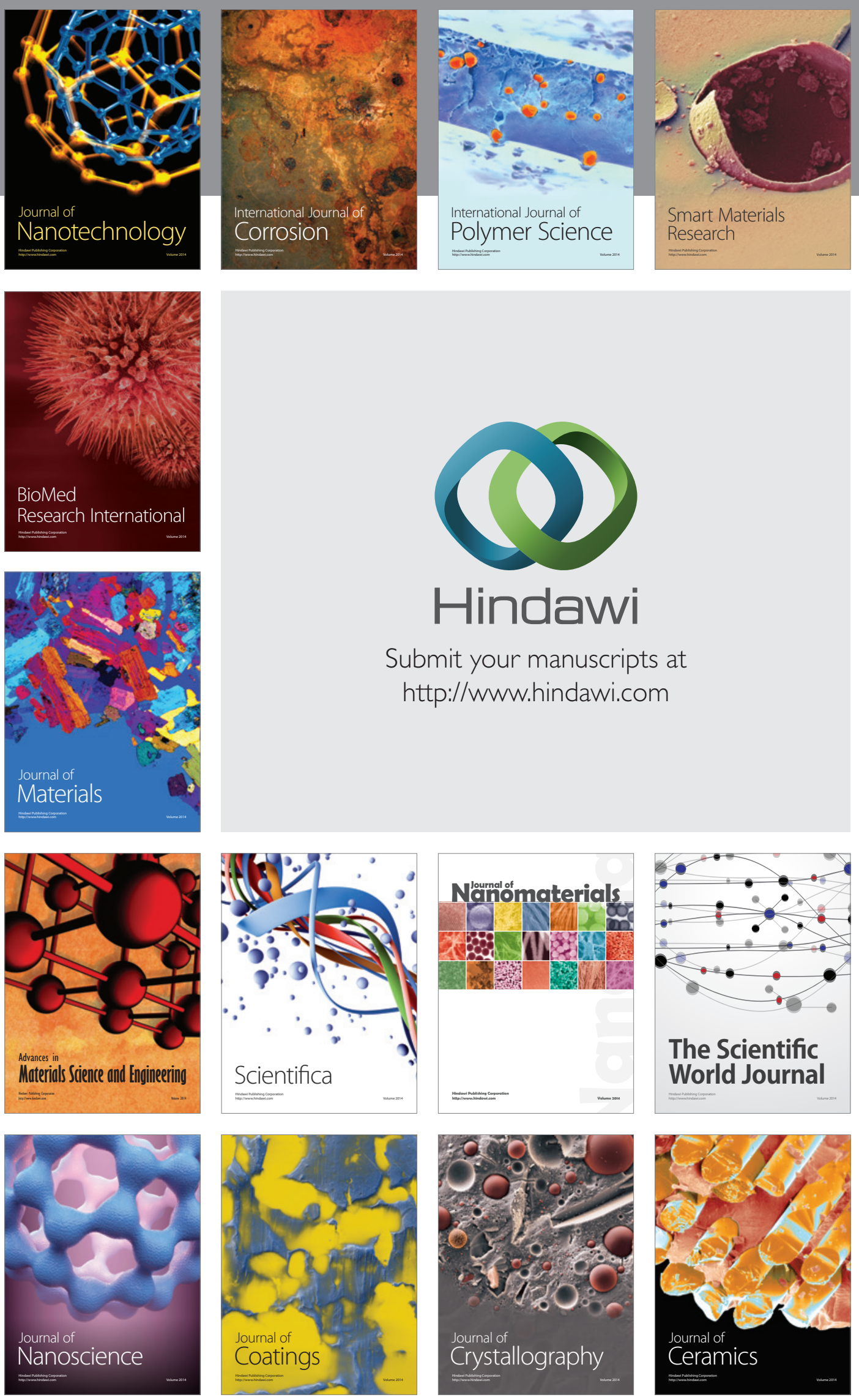

The Scientific World Journal

Submit your manuscripts at

http://www.hindawi.com

\section{World Journal}

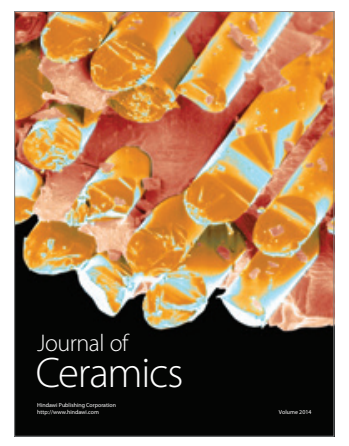

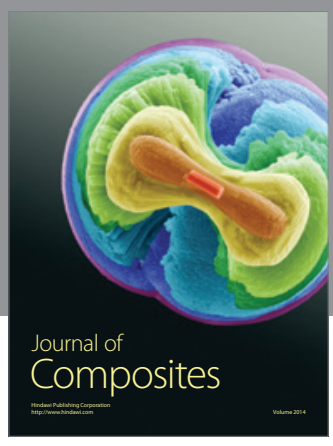
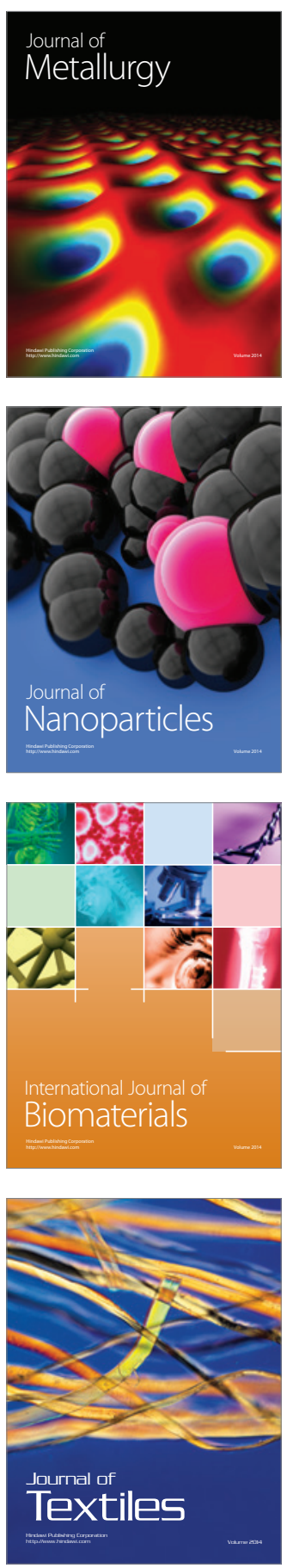